\title{
Treating the Medicare Population in a Clinic Setting
}

Alexandria Jauregui-Dusseau, DHSc, LAT, ATC; McCall Christian, DAT, LAT, ATC

Missouri State University

\section{Key Phrases}

Clinic and hospital patient population, organization and personal outcomes, comorbidities, geriatric, rehabilitation

\section{Correspondence}

Dr. Alexandria Jauregui-Dusseau, Missouri State University 901 S. National Avenue, Springfield, MO 65897

Email: dus10@missouristate.edu

\section{Full Citation}

Jauregui-Dusseau J, Christian M. Treating the Medicare

Population in a Clinic Setting. Clin Pract Athl Train.

$2021 ; 4(3): 28-33$

https://doi.org/10.31622/2021/0004.3.5.

Submitted: October 6, 2020 Accepted: September 20, 2021

\section{COMMENTARY}

\section{Athletic training started as a profession specific}

to sports and caring for the health and well-being of athletes within a specific institution. Today, athletic trainers serve across the healthcare network in areas such as physician offices, industrial warehouses, tactical settings and performing arts. The profession has continued to expand its scope of training from a role in first aid and emergency care to incorporate comprehensive rehabilitation and prevention, ergonomic evaluations, and assistive roles within an orthopedic surgical setting. The required education needed to obtain certification in the profession has transformed from a secondarylevel teaching credential with preparations in athletic training to now a professional-master's level education curriculum and many postprofessional doctorate and residency programs across the country. ${ }^{1}$

The practice and education of athletic training has progressed leading to the transformation in the population the profession treats. As a result, state practice acts are changing to accommodate the expanding patient populations. With a focus in pediatric and active populations, geriatric sectors often are not seen by athletic trainers due to being primarily treated by other rehabilitation specialties. A contributing factor is the lack of reimbursement and recognition in the Medicare Services sector.

As a part of a funded research grant, the research team began collecting both patient-rated and clinician-rated outcome measures on the Medicare-eligible population treated by an athletic trainer to understand the effect of athletic training rehabilitative services. Patients were categorized based off their chief concern (lower extremity, knee, spine, upper extremity), which dictated the outcome measures that were collected. Complete characteristics of the research participants are reported in Table 1. The outcome measures were gathered based on developer suggestions for frequency. The intent for this project was to provide data that could facilitate recognition from Medicare Services. Patients who volunteered for this study had no difference in their intended treatment plan, but rather, more intentional outcomes were collected to understand the perspective of their recovery. Taking a patient-centered approach at caring for this population was a high priority. The structure of this research has led to a new perspective of what it takes to treat a novel population in the field of athletic training.

\section{PREPARATION FOR THE STUDY}

Understanding the Needs of the Population

The Medicare-eligible population is a unique population to work with as an athletic trainer in the orthopedic rehabilitation clinic setting. Typically, the patient population ranges from seven to sixty years old, and their co-morbidity list is fairly short. The needs are unique, and it has required more preparation and research to 
refresh the understanding of co-morbidities specific to the Medicare-eligible population. Additionally, these patients have had more experiences in the healthcare system. Some of those experiences could have negatively influenced their perception of healthcare providers. For instance, this population is subject to ageism and are treated differently by providers intentionally or unintentionally because of their age. Ageism within healthcare is described by Ugurlu et $\mathrm{al}^{2}$ as having preconceived notions and prejudices against the elderly population. Studies have been conducted in a variety of healthcare disciplines to understand the intention and influences behind an ageist perspective. ${ }^{2,3,4}$ A study by Ben-Harush et al. ${ }^{3}$ found commonalities among a few healthcare professions and the prevalence of ageism. ${ }^{3}$ Healthcare providers do not necessarily intend to treat older patients differently or inadequately, but the presence of implicit bias toward a patient's age and ineffective communication strategies impact the care provided to this population. ${ }^{2}$ With this understanding, it was made a priority to treat these patients with the respect that would be given to any other patient, but also to be cognizant of unconscious ageism. It was important to keep the expectations of these patients high and did not let their age affect the goals we set, or they set for themselves.

\section{Considering Common Preexisting Conditions}

A significant adjustment to working with the Medicare-eligible population was understanding medical diagnoses not familiar to the clinician and how those diagnoses would affect their recovery. Co-morbidities prevalent among the aging population were foreign to the treating clinician and are not extensively discussed in athletic training curriculums. Patients with progressing Parkinson's disease, hearing loss, osteoarthritis, auto-immune disorders, degenerative joint disease, and malignant cancer diagnoses were now being evaluated and treated by an athletic trainer. Another consideration for the clinician was that they were working against decades of learned habits and postures. This required creative thinking and learning how to tailor the treatment approach to meet that patient where they were in terms of mobility and functional ability.

Most of the patients had some degree of joint degeneration and corresponding range of motion restriction. The immobility and range of motion loss could be attributed to previous history of injuries and surgeries as well as a lack of use of full, end range motion. A priority for many of these patients has been to restore their functional mobility, strength, and overall movement. It was imperative to maintain high expectations for every patient regardless of their functional capacity. There were many situations where patients were reluctant to try an activity, especially getting down and up from the floor or picking items off the ground. Although they were active, many were not in the habit of performing these seemingly trivial tasks and were not confident in performing it independently. This was expressed through reporting lower health-related quality of life perceptions and disappointment in their ability to freely move. Integrating transitional movements into treatment sessions, such as frequently moving from supine to a standing position, became a goal included in the patient's treatment plan.

Another aspect considered when working with this population is how immobility and a lack of independence affected their overall healthrelated quality of life. For example, if a patient is unable to exercise due to pain, functional limitation, or a mechanical restriction, existing comorbidities could be exacerbated or developed from that lack of movement and sedentary lifestyle. Several study participants expressed their concern of worsening blood pressure, weight gain, and general mental well-being due to an inability to perform their exercise routine. 
Table 1. Patient Demographics

\begin{tabular}{lccc}
\hline \multicolumn{1}{c}{ Variable } & $\mathbf{n}$ & $\%$ & $\mathbf{M}$ \\
\hline Age & - & - & 69.6 \\
Gender & & 50 & - \\
\hline$\quad$ Female & 49 & 50 & - \\
$\quad \begin{array}{l}\text { Male } \\
\text { Chief Concern }\end{array}$ & 49 & 37.76 & - \\
\hline$\quad$ Lower Extremity & 37 & 22.45 & - \\
$\quad$ Knee & 22 & 34.69 & - \\
$\quad$ Upper Extremity & 34 & 5.10 & 13.9 \\
$\quad$ Back & 5 & - & \\
\hline Length of Stay (weeks) & - & & \\
\hline
\end{tabular}

a Lower extremity encompassed hip, lower leg, ankle, and foot injuries.

Increasing the patient's freedom of movement is essential to maintaining overall health and wellbeing throughout the remainder of their lifespan.

Prior to the clinician's involvement in this research project, her knowledge of Parkinson's disease was limited. That changed drastically after working with three patients who have been battling this disease for several years. Parkinson's disease presents differently in each patient, and they all managed it in their own way. Although they were referred for a musculoskeletal injury, the disease profoundly affected the treatment approach. For instance, the first patient with Parkinson's disease that participated in the study had a significant tremor in the upper extremity and had made the personal decision to not take any medication that would lessen the intensity of the tremor. She became accustomed to working with the tremor and adjusting manual therapy techniques and therapeutic activities. However, even when working with a different patient that was on medication to reduce the severity of their tremors, the daily treatment plan would be affected by when the medication was taken or if was not taken that day.

Hearing loss is common issue that affects the Medicare-eligible population. The therapy area is a large, open workspace with ten clinicians treating patients. This environment can make it difficult to hear when conversing with patients. It is important to pay special attention to communicating effectively and respectfully with

Copyright (C) by Indiana State University patients that suffered from hearing loss. To enhance communication between clinician and the patient, the implementation of strategies such as maintaining eye contact, using concise descriptions, and expanding teaching styles by providing visual and tactile cues and examples. Communicating in a respectful way that does not make the patient feel uncomfortable or embarrassed is key to building a strong rapport with the patient and earning their trust.

Another consideration in treating the geriatric population is exposure to extensive medical histories and chart entries that were unfamiliar. The healthcare provider list is more extensive, and the patient might be undergoing active treatments for co-morbidities. In many cases, the treating clinician had to refresh their knowledge of lesser seen diagnostic and lab outputs. Additionally, medication lists for this population are also more intensive and it is important to consider how they affect treatment. For instance, the tissue of a patient that is on blood thinners will react differently to instrument-assisted manual therapy and the provider must pay attention to these skin reactions. Interprofessional collaboration was essential when working with these patients, not only to stay updated about evolving issues, but also to provide those providers with information about a patient's progress and how it ties into their overall health profile. Building relationships with referring physicians and other members of the patient's health care team is a practical

Clinical Practice in Athletic Training Volume 4 - Issue 3 - November 2021 
strategy to familiarize oneself with a specific patient and to better understand the extensive health histories of geriatric patients.

\section{COMMON CHALLENGES}

Working with a population that is vastly different from which is commonly associated to athletic training was a unique and challenging experience. These patients present with a variety of pre-existing conditions, complex medical histories, and may have had negative experiences within healthcare. Unfortunately, geriatric patients are subject to lower expectations due to societal norms and ageism. Stereotypes against Medicare-eligible patients can significantly affect their care and how they are treated by healthcare providers. 2,3 For example, a clinician exhibits an ageist attitude if they decide to "take it easy" on an elderly patient and lower their standards of what constitutes full function. On more than one occasion in working with these patients, they have made comments about how they were treated by other providers and how they felt about the expectations set for them because of their age. These patients are very aware of how their treatment plan is dictated by their age and many of them aspire beyond the conservative plans of a clinician. Another sentiment expressed by our patients is how some providers expressed that their issue was "just due to their age" and could not be remedied. Prior experiences like this shaped their perception of healthcare providers and healthcare in general. It presented the challenge to earn their trust and change their mind about health care providers and increase their knowledge of athletic trainers.

\section{BENEFITS TO THE CLINICIAN AND THE POPULATION}

Exposure to this population has created the opportunity to expand knowledge and to provide quality care to a deserving population. In every patient encounter, the clinician strived to instill confidence in their abilities and facilitate a sense of ownership over their healthcare journey. Promoting elevated expectations among this population can improve their perspective of longterm care, functionality, and success in rehabilitation. Conversations with the patients have indicated that there are gaps in rehabilitation care and there is limited focus on returning to functional and recreational activities. Patients expressed that past therapy experiences mostly focused on returning to activities of daily living and did not address more dynamic activities. At the conclusion of participation, each individual was asked to complete a patient satisfaction survey. Over fifty participants used the open comment box to express written strength and weaknesses. Table 2 shows a compilation of these comments. Agreeing on patient goals and the treatment plan must be a collaborative process and should not be determined solely on a patient's Medicare status or age.

\section{CONCLUSION}

Athletic trainers are not known for treating geriatric patients but are more than capable of providing quality care to this population. Considerations must be made to complex medical histories and co-morbidities, but the expectations of what a geriatric patient can achieve should not be underestimated. Gaining access to this population would be a multi-faceted process and would require cooperation from various entities and stakeholders. This research study has indicated what this patient population values in their therapy experience and has yielded outcomes that demonstrate the effectiveness of athletic trainer provided services to this population through patient satisfaction scores and patient-reported outcomes. This patient population needs comprehensive therapy that strives to improve their entire movement profile, address the whole-person, and improve overall capacity to engage in physical activity across their lifespan. It is a worthwhile endeavor to ensure that 
Table 2. Themes in Patient Satisfaction Responses with Quotes

\begin{tabular}{|c|c|}
\hline Personal Attention: & $\begin{array}{l}\text { - Took a personal interest in me and remembered things from one } \\
\text { visit to the next. Very professional but made me feel like I was her } \\
\text { only client. } \\
\text { - Personalized attention. } \\
\text { - Has been a very professional, personable experience. } \\
\text { - Very professional but also very personable. } \\
\text { - The care taken to address my unique needs at each session - it } \\
\text { - } \text { was definitely "patient driven" as opposed to "program driven." } \\
\text { - Pelped my hip problem and I finally go answers. } \\
\text { - } \text { carenal touch was good. Showed me lots of new stretches. Felt } \\
\text { The athletic trainer is very personable and professional. }\end{array}$ \\
\hline Focus on Whole-Person: & $\begin{array}{l}\text { - Physical/intellectual/emotional blend of support. Excellent. } \\
\text { - The attention of my aches, regardless of its location, whether it is } \\
\text { part of original problem or not. Allowing me to be me during } \\
\text { entire process (humoring me when I ask sideways questions ("what } \\
\text { the muscle called?")) It is easy to feel 'old' when surrounded by } \\
\text { youth-I never felt old. } \\
\text { - Excellent listening, care, suggestions, knowledge... friendliness. } \\
\text { - Interested in my total welfare. Very friendly. }\end{array}$ \\
\hline $\begin{array}{l}\text { Established Relationship/ } \\
\text { Compassion: }\end{array}$ & $\begin{array}{l}\text { - The athletic trainer was patient and caring! } \\
\text { - Compassion for the client/patient. } \\
\text { - Empathy. } \\
\text { - Loved the care and rapport with the athletic trainer. } \\
\text { - Rapport, concern with meeting my needs. } \\
\text { - Kindness and empathy. }\end{array}$ \\
\hline
\end{tabular}

these patients receive quality care and continue to perform functional activities without limitation.

\section{REFERENCES}

1. National Athletic Trainers' Association. History. 2020. Available at: https://www.nata.org/history\#: :text=T he $\% 20$ National $\% 20$ Athletic\% $\% 20$ Trainers '\%20Association,the $\% 20$ future $\% 20$ of $\% 2$ Otheir\%20profession.
2. Ugurlu Z, Kav S, Karahan A, Akgun Citak E. Correlates of Ageism Among Health Care Professionals Working with Older Adults. J Transcult Nurs. 2019;30(3):303312.

http://doi.org/10.1177/10436596188 10128.

3. Ben-Harush A, Shiovitz-Ezra S, Doron I, et al. Ageism among physicians, nurses, and social workers: findings from a qualitative study. Eur J Ageing. 2017;14(1):39-48. http://doi.org/10.1007/s10433-0160389-9. 
4. Blackwood J, Sweet C. The influence of ageism, experience, and relationships with older adults on physical therapy students' perception of geriatrics. Gerontol Geriatr Educ. 2017;38(2):219231.

http://doi.org/10.1080/02701960.20 15.1079709. 